\title{
WHO's global strategy on diet, physical activity and health
}

\author{
Response to a worldwide epidemic of non-communicable diseases
}

\author{
Amalia Waxman \\ World Health Organization (WHO), Geneva, Switzerland
}

\section{Abstract}

\begin{abstract}
World health is in transition. Epidemiologically, many low- and middle-income countries are now experiencing a double burden of disease, whereby in addition to infectious diseases, they are facing a growing toll of death and disability from non-communicable diseases (NCDs). The world population is aging, while increased development has been accompanied by rising disposable incomes, urbanization, mechanization and the globalization of food markets, leading to lifestyle and behaviour changes that adversely impact population health. These lifestyle changes include dietary changes (nutrition transition), reduced physical activity levels and increased tobacco use. The result of these changes is that NCDs are increasing at alarming rates globally. The burden of NCDs in developing countries already outweighs that of communicable diseases, both in countries with high and low mortality. In 2002, NCDs accounted for $60 \%$ of total mortality worldwide and $46 \%$ of the global burden of disease. In May this year, the World Health Organization's full membership is scheduled to consider or adopt the WHO Global Strategy on Diet, Physical Activity and Health, which provides countries with a wide-ranging set of policy options to address these key NCD risks.
\end{abstract}

\section{Background}

In May this year, the World Health Organization's full membership is scheduled to consider or adopt the WHO Global Strategy on Diet, Physical Activity and Health. This followed almost two years of strategy development and extensive consultation with stakeholders, which included the extension of the period for Member State comments up until February 29, 2004. Some 55 additional comments were received, placed on the WHO web site and were taken into account by the WHO secretariat in finalising its draft.

The strategy is an important global public health initiative, prompted by Member State concern at the explosion in non-communicable diseases (NCDs), for which unhealthy diet and physical inactivity are, together with tobacco use, among the key risk factors.

World health is in transition. Epidemiologically, many low- and middle-income countries are now experiencing a double burden of disease, whereby in addition to infectious diseases, they face a growing toll of death and disability from NCDs. The world population is aging, while increased development has been accompanied by rising disposable incomes, urbanization, mechanization and the globalization of food markets, leading to lifestyle and behaviour changes that adversely impact population health (1, $2)$. These lifestyle changes include dietary changes (nutrition transition), reduced physical activity levels and increased tobacco use.

The result is that NCDs are increasing at alarming rates globally. The burden of NCDs in developing countries already outweighs that of communicable diseases, both in high- and lowincome countries. In 2002, NCDs accounted for $60 \%$ of total mortality worldwide and $46 \%$ of the global burden of disease (3). Countries with low and high mortality account for the increase in the burden of disease from NCDs. One example comes from China. In China's rural areas - and that's still more than 800 million people - NCDs account for more than 80 percent of deaths; communicable diseases, less than three percent $(4,5)$.

Only in Africa do deaths from communicable diseases outweigh those from NCDs: in WHO's other five regions, NCDs now dominate. Of the estimated 57 million deaths which occur each year, 33.4 million are attributed to NCDs. Of these, 16.7 million are attributed to cardiovascular diseases 
(CVDs), especially ischaemic heart disease and cerebrovascular diseases. Twice as many people die from CVDs in developing countries as in developed countries. Obesity is now a global epidemic, (6). with more than 1 billion overweight people and at least 300 million of them clinically obese. The number of people with type 2 diabetes is expected to increase almost three-fold by 2020, and most of this growth is projected to occur in Asia. In India alone there are currently close to 33 million diabetics.

\section{The causes of non-communicable diseases}

As noted, NCDs are increasing for several key reasons. Throughout the world, birth rates are declining, life expectancy is increasing and populations are aging. Between 1955 and 2002, life expectancy at birth in low-mortality developing countries rose from approximately 42 to 70 years (3). These demographic changes can be explained by significant improvements in both medical science, technology, and successful public health and other development efforts over the last 100 years.

The world population exposure to the modifiable risk factors for cardiovascular diseases, cancer, type 2 diabetes, obesity and other NCDs is also increasing at a very rapid pace (7) Five of the top 10 global disease burden risk factors identified by the World Health Report 2002 - high blood pressure, high cholesterol, low intake of fruit and vegetables, high body mass index and physical inactivity - independently and often in combination, are the major causes of these diseases.

The increased prevalence of modifiable risk factors is closely linked to economic development. Urbanization is key to understanding lifestyle changes. Rapid growth of urban centres results, in most parts of the world, in deficiencies in housing, infrastructure, and basic services. This trend is accompanied by growing influences of global trade, industrialization and expansion of food markets. Populations are exposed to increased availability and aggressive promotion of processed, inexpensive food - generally high in fats, sugar and salt - but reduced access and affordability of fruits and vegetables. For every $10 \%$ increase in income, the proportion of energy intake from fat is increasing faster among the poor than the rich in China (8). Diet-related NCDs are not only the biggest killers, but they also reflect socio-economic inequalities, e.g. NCDs and their risks tend to cluster heavily among the poorest communities in all countries, and in developing countries they occur, on average, at lower ages $(9,10)$.

\section{A global epidemic}

This is, therefore, a global epidemic and requires a global response. With the approval of the strategy, developing countries will have the tools to ensure they do not experience the high peak in NCD prevalence that has occurred in the developed world. To ensure the strategy responded to country needs, six WHO regional consultations with Member States were completed between March and June 2003. The strategy also reflects the expertise and advice of several United Nations organizations, in particular the Food and Agriculture Organization. WHO has also received significant input from representatives of civil society and non-governmental organizations, and from the private sector. WHO has been supported in this process by a reference group of prominent experts from all over the world, representing several fields and disciplines.

The strategy builds upon the vast evidence, best practices and experience in countries in tackling and preventing NCDs. It also draws on the experience and knowledge of health, nutrition and physical activity experts from a wide range of disciplines and countries, both developed and developing. One of the strategy's most important conclusions is that reducing the burden of NCDs requires a multisectoral, multi-stakeholder approach. The strategy is not prescriptive, but rather provides WHO Member States with a comprehensive toolbox of policy options from which to choose.

\section{References}

1. Popkin BM. Urbanization, lifestyle changes and the nutrition transition. World Development 1999; 27: 1905-16.

2. Bell AC, Ge K, Popkin B. The road to obesity or the path for prevention: motorized transportation and obesity in China. Obesity Research 2002 April; 10(4).

3. WHO. Shaping the Future, The World Health Report 2003.

4. Ruitai S. The Challenge of epidemiology transition in China. Chinese Preventive Medicine 2001.

5. Ruitai S. Epidemiology transition in China. East meets west for 21 century, Sino-America medical conference, June 27, 2001, Boston. 
6. WHO. Obesity: Preventing and managing the global epidemic, Report of a WHO consultation, WHO Technical Report Series, No. 894, 2000.

7. WHO. Reducing Risks, Promoting Healthy Life, Geneva, World Health Organization, World Health Report 2002.

8. Popkin BM, Du S. Dynamics of the nutrition transition toward the animal foods sector in China and its implications: a worried perspective. J Nutr 2003; 133: 3898.

9. Monteiro CA, Wolney LC, Popkin BM. The burden of disease from undernutrition and overnutrition in countries undergoing rapid nutrition transition: a view from Brazil. Am J Public Health 2004; 94(3): 433-4.
10. Caballero B. Introduction. Symposium: Obesity in developing countries: biological and ecological factors. J Nutr 2001 131(3): 866S-870S.

Amalia Waxman, Project Manager

Global Strategy on Diet

Physical Activity and Health

World Health Organization

20 Avenue Appia

$\mathrm{CH}-12$ II Geneva

Switzerland

E-mail: waxmana@who.int 